\title{
ACUTE FEBRILE REACTION COMPLICATING SPINAL ANAESTHESIA IN A SURVIVOR OF MALIGNANT HYPERTHERMIA
}

\author{
Jonathan D. Katz and Leonard B. Krich $†$
}

MaLignaNT hYPERPYHEXIA is an increasingly reported complication of general anaesthesia.

With heightened awareness of this entity and earlier recognition, some workers have shown considerable improvement in the grim mortality figures.

The few survivors pose a challenging problem for the anaesthetists when they appear for their next surgical procedure. Because malignant hyperpyrexia has been reported with virtually all general anaesthetic techniques, several authors have recommended the use of conduction anaesthesia in these individuals whenever possible. $^{1}$

This report describes a patient who survived an episode of malignant hyperpyrexia, then suffered an acute febrile reaction during a subsequent spinal anaesthetic.

\section{Case Report}

A twenty-six-year-old black male was admitted for elective repair of a right inguinal hernia, symptomatic for one month.

Previous operations included a left inguinal hernia repair in 1966 under general anaesthesia and haemorrhoidectomy in 1971 under spinal anaesthesia. Both were uneventful. The patient had a history of mild alcohol abuse. There was no history of other illness.

The patient's mother had one anaesthetic exposure, during the birth of the patient and his twin sister. After repeated close questioning, the mother recalled being told that she had suffered a high fever during the course of this anaesthetic. The twin sister died at age seven months of failure to thrive. There is a family history of high blood pressure.

The patient was moderately obese. Blood pressure was $130 / 90 \mathrm{~mm} \mathrm{Hg}$, pulse 72 beats $/ \mathrm{min}$, temperature $99^{\circ} \mathrm{F}$ and weight $89 \mathrm{~kg}$. There was bilaterally symmetrical expothalamus (a family characteristic and present during the patient's entire life). There was a right inguinal hernia. Neurological examination and the remainder of the physical examination were normal.

On admission, laboratory data including haemoglobin, white blood count, urine analysis, serum electrolytes, and chest X-rays were all normal except: VDRL positive $\times 3$ (FTA negative), calcium $12.5 \mathrm{mg} \%$ (upper limit normal $10.5 \mathrm{mg} \%$ ) and uric acid $9.8 \mathrm{mg} \%$ ( upper limit normal $8.0 \mathrm{mg} \%$ ).

"Jonathan D. Katz, M.D., Department of Anesthesiology, Yale University School of Medicine, 333 Cedar Street, New Haven, Connecticut 06511.

tLeonard B. Krich, M.D., USPHS Hospital, Staten Island, New York. 


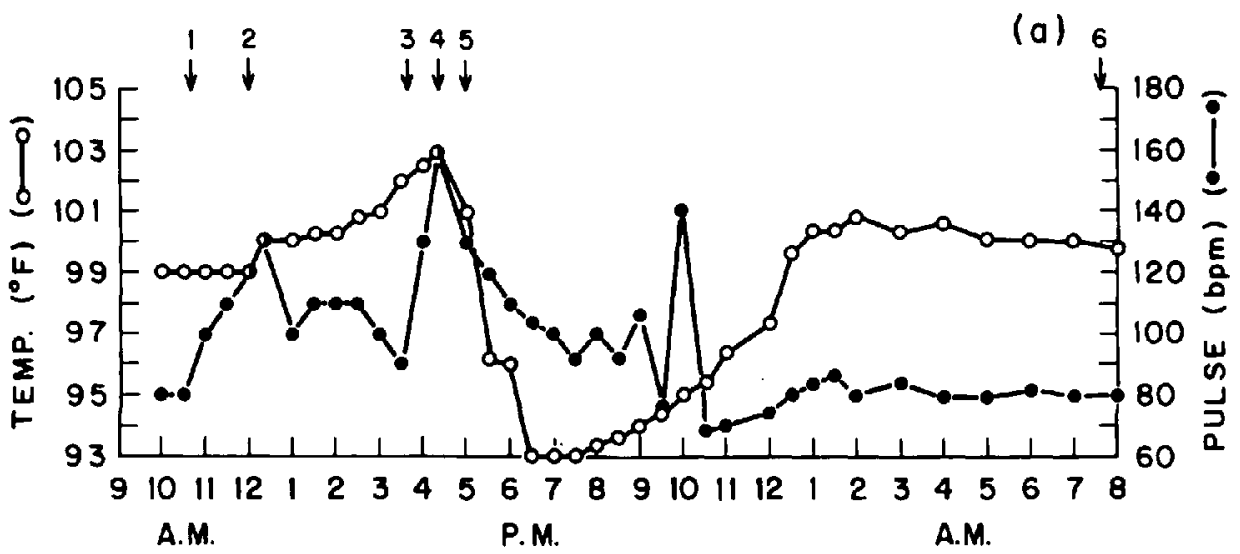

Figure 1. Parathyroid Exploration - (1) induction of anaesthesia, (2) surgical incision, (3) hypothermic measures begun, (4) operation terminated. Patient to recovery room where he was placed in an ice bath and on a mechanical ventilator, (5) out of ice bath, (6) patient awake and alert.

Because of the persistently elevated calcium, the herniorraphy was postponed and the hypercalcaemia was further investigated. Approximately two weeks after admission, he underwent parathyroid exploration. An adenoma was removed from the right inferior parathyroid. A normal biopsy was taken from the left superior parathyroid. The other two parathyroid glands were not identified because of the necessity to terminate the operation prematurely. The thyroid gland appeared normal.

The patient was medicated preoperatively with sodium pentobarbitone $100 \mathrm{mg}$, diazepam $10 \mathrm{mg}$, and atropine $0.6 \mathrm{mg}$ intramuscularly. Induction was accomplished with droperidol $17.5 \mathrm{mg}$ and fentanyl $0.6 \mathrm{mg}$ intravenously. D-tubocurarine $6 \mathrm{mg}$ and succinylcholine $80 \mathrm{mg}$ were administered intravenously for intubation. The trachea was sprayed with $5 \mathrm{cc}$ of lidocaine 1 per cent through an atomizer and the intubation was accomplished without difficulty. There was good muscle relaxation, and no muscle rigidity was noted. The remainder of his operative course is outlined in Figure 1. By 4:15 p.m. his temperature had reached $102.5^{\circ} \mathrm{F}$. The surgeons were instructed to terminate the procedure and the patient was transported to the recovery room, where vigorous hypothermic measures were undertaken. He was placed in an ice bath and ventilated with 60 per cent $\mathrm{O}_{2}$ with a mechanical ventilator. He was given chlorpromazine (total dose $37.5 \mathrm{mg}$ ), d-tubocurarine $60 \mathrm{mg}$, procainamide $300 \mathrm{mg}$, sodium bicarbonate $110 \mathrm{meq}$, hydrocortisone sodium succinate $300 \mathrm{mg}$, and sodium iodide $1 \mathrm{~g}$. The blood gases in the first sample taken in the recovery room were $\mathrm{P}_{\mathrm{O}_{2}} 58, \mathrm{P}_{\mathrm{CO}_{2}} 38, \mathrm{pH} 7.41$. The fever rapidly defervesced and he was removed from the ice bath approximately 35 minutes after arrival in the recovery room. The ventilator was set at 100 per cent $\mathrm{Fi}_{\mathrm{o}_{2}}$ and blood gases were $\mathrm{P}_{\mathrm{O}_{2}} 280, \mathrm{P}_{\mathrm{CO}_{2}} 48, \mathrm{pH} 7.59$. His temperature fell as low as $93^{\circ} \mathrm{F}$ and slowly returned toward normal with the aid of a heating blanket. The following morning he was afebrile, with stable vital signs, awake and alert. Blood gases on 40 per cent oxygen with a T-piece were $\mathrm{pH} 7.43, \mathrm{P}_{\mathrm{O}_{2}} 107.3, \mathrm{P}_{\mathrm{CO}_{2}} 44$. At 8 a.m. the morning following operation he was extubated and ambulated. The remainder of his postoperative course was entirely uneventful and he had little complaint except for some minor stiffness. 


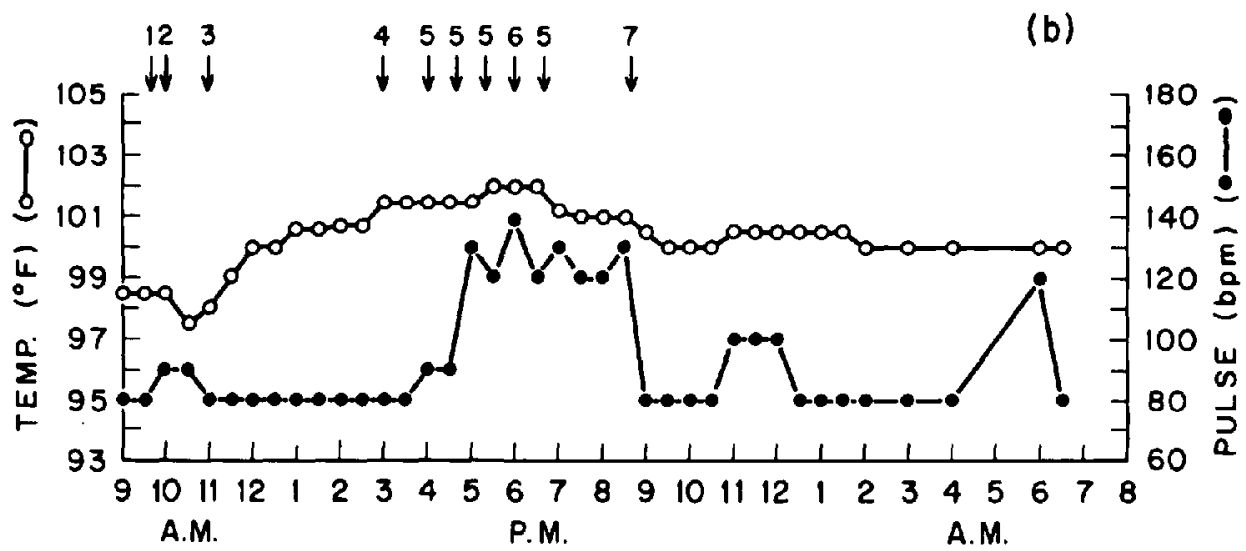

Frgune 2. Inguinal Herniorraphy - (1) spinal anaesthesia administered, (2) procaine local anaesthesia, surgical incision, (3) operation completed, (4) aspirin suppository, (5) chlorpromazine ( $25 \mathrm{mgm}$ ) intravenously, (6) hypothermia blanket on, (7) hypothermia blanket discontinued.

Thyroid related blood chemistry and urinary catecholamines in specimens collected during the acute febrile episode and repeated for several weeks postoperatively were normal. Serum creatine phosphokinase determined ten days postoperatively was $115 \mathrm{IU} / \mathrm{L}$ (normal 8-88 IU/L). The calcium returned to normal levels postoperatively.

The patient's inguinal hernia remained symptomatic. After careful discussion among the staff and with the patient, it was elected to perform a right inguinal herniorraphy under spinal anaesthesia. The operation was done 20 days after his first episode of malignant hyperpyrexia. The course of this anaesthetic is outlined in Figure 2.

The patient received no preoperative medication. He arrived in the operating room extremely anxious. A small skin wheal was made with $0.5 \mathrm{cc}$ of 1 per cent lidocaine prior to the insertion of a peripheral venous cannula. Spinal puncture was performed with a great deal of difficulty and a free return of cerebrospinal fluid was not obtained. Tetracaine $10 \mathrm{mg}$ was instilled. "Spotty" anaesthesia to the level of the second lumbar dermatome was obtained which was not adequate for the operation and repeated local infiltrations of procaine 0.5 per cent were required (total dose $120 \mathrm{mgm}$ ). An œsophageal temperature probe was passed after being lightly lubricated with 5 per cent lidocaine ointment. No other medication was administered in the operating room.

Upon arrival in the recovery room at 11 a.m., one hour after the induction of anaesthesia, he was afebrile and all vital signs were stable. There was a gradual rise in temperature and blood pressure and at $3: 30$ p.m. he received aspirin $600 \mathrm{mg}$, per rectum, and morphine $4 \mathrm{mg}$ intravenously and shortly afterwards phentolamine $1 \mathrm{mg}$ intravenously and $4 \mathrm{mg}$ intramuscularly. When his temperature rose to $102^{\circ}$ $\mathrm{F}$ at 5.30 p.m., despite these measures, he was given chloropromazine (total dose $75 \mathrm{mgm}$ ) intravenously and was placed on a cooling blanket. His temperature began to fall slowly after application of a hypothermia blanket, which was discontinued when his temperature reached $101^{\circ} \mathrm{F}$. He was completely stable and afebrile by the following morning.

The remainder of his hospitalization was totally uneventful. 


\section{Discussion}

The entity commonly called "malignant hyperpyrexia" is an ill-defined clinical syndrome. The one feature which all cases have in common is a fulminant hyperthermia (to temperatures as high as $112^{\circ} \mathrm{F}$ ) usually occurring within five hours after induction of anaesthesia.

The syndrome is commonly subdivided into two varieties, rigid and non-rigid, to describe the presence or absence of generalized skeletal muscle rigidity.

The case presented in this paper demonstrates some of the features ascribed to the non-rigid type. The rapid temperature elevation was accompanied by tachycardia, hypertension and hypoxia. No acidosis was demonstrated. This was probably obscured by the large doses of buffer which had been given empirically. No electrolyte disturbance was recorded except elevated serum calcium which prompted the parathyroid exploration. Serum creatine phophokinase (CPK) was elevated nearly two weeks after operation. There was a family history suggestive of a similar episode involving the patient's mother.

The second operation under spinal and local anaesthesia was complicated by a febrile reaction with a time course remarkably similar to the first episode. Because of the shorter duration of the second operation the hyperthermia appeared postoperatively in the recovery room. This fact and the earlier therapy for smaller temperature elevations, perhaps helped to moderate this febrile reaction.

Conduction anaesthesia is generally recommended when surgery is required in a patient who has previously suffered an episode of malignant hyperpyrexia under general anaesthesia. ${ }^{1}$ It has recently been shown that epidural anaesthesia with lidocaine can abort the onset of malignant hyperpyrexia in susceptible swine. ${ }^{2}$ In our review of the literature, there have been no previous reports of malignant hyperpyrexia occurring with spinal anaesthesia. There is one brief mention of an episode occurring during epidural anaesthesia and of one occurring with local anaesthesia, although details are not supplied. ${ }^{3}$

There is some experimental and theoretical basis to believe that certain local anaesthetic agents, procaine and tetracaine for example, are beneficial in the treatment of a case of the rigid variety of malignant hyperpyrexia. ${ }^{3}$ On the other hand, other local anaesthetics, for example lidocaine, probably exacerbate an episode.

The mechanisms involved in the evolution of the non-rigid variety of malignant hyperthermia appear to be markedly different from those associated with the rigid type. It has been suggested that local anaesthetic agents of any type should be avoided in patients susceptible to non-rigid malignant hyperthermia. ${ }^{3}$ In our patient's second anaesthetic exposure, the only agents used were local anaesthetics: tetracaine $10 \mathrm{mg}$ for spinal anaesthesia, procaine $120 \mathrm{mg}$ for local infiltration, lidocaine $5 \mathrm{mg}$ for local infiltration and viscous xylocaine (lidocaine) $2 \mathrm{mg}$ topically for œsophageal temperature probe. These agents may have contributed to this patient's acute febrile response.

Several authors have recently pointed out a possible association of psychic stress and the onset of malignant hyperthermia in $\operatorname{man}^{4}$ and in animals. ${ }^{5}$ This argument implicates some of the physiological responses to anxiety as a triggering or facilitat- 
ing factor in a febrile episode in susceptible individuals. Our patient was extremely anxious before and during his second operation. This may have played a role in his subsequent acute hyperthermia.

\section{SUMMARY}

A case report is presented of a survivor of malignant hyperthermia who suffered an acute febrile episode during the course of a spinal anaesthetic. It is suggested that the extreme degree of intra-operative anxiety may have triggered this event.

\section{RÉSUMÉ}

Vingt jours après un épisode d'hyperthermie survenu sous anesthésie générale et traité avec succès, un malade a été opéré sous rachi-anesthésie pour cure de hernie. Il a présenté dans les heures suivant sa rachi-anesthésie un épisode fébrile qui a bien répondu au traitement. L'auteur suggère que l'extrême anxiété manifestée par le malade durant la deuxième intervention peut avoir été un facteur déclenchant.

\section{REFERENCES}

1. Britt, B.A. \& Gondon, R.A. Three cases of malignant hyperthermia with special consideration of management. Canad. Anaesth. Soc. J. 16: 99-105 (1969).

2. KERR, D.D., et al. Prevention of porcine malignant hyperthermia by epidural block. Anesthesiology 42: 307-311 (1975).

3. Burt, B.A. Recent advances in malignant hyperthermia. Anesth. \& Analg. 51: 841-850 (1972).

4. Lister, D. Malignant Hyperthermia: A human and porcine stress syndrome. Lancet 1: 519 (1975).

5. Wingard, D.W. Malignant Hyperthermia: A human stress syndrome. Lancet, 1450-1451 (1974). 